\title{
Cảm nhận lịch sử theo cách của người có tuổi
}

\author{
Vương Quân Hoàng
}

Ngày 10 tháng 7 năm 2021

Nhân ngày có việc công với Nhà xuất bản Chính trị Quốc gia, vài cảm nhận cá nhân trở nên rõ rệt hơn về thời gian và cách hiểu về lịch sử (sự kiện, công việc và cuộc đời).

Công việc ngày hôm nay liên quan tới việc tái bản cuốn sách Kinh tế Việt Nam: Thăng trầm và đột phá. Cảm giác cứ như lần xuất bản trước vẫn "mới đây thôi". Ấy thế mà cũng đã hơn 12 năm trôi qua kể từ khi hoàn thành việc xuất bản.

Hơn một thập kỷ nào phải ngắn, nếu không nói là rất dài. Với cầu thủ bóng đá, đó có thể là một thế hệ sân cỏ. Với một nhà nghiên cứu xã hội, thời gian đó có thể đủ (thậm chí dử) để hoàn thành những tác phẩm tâm nguyện cho đời mình. Ngẫm tiếp sẽ thấy sự kỳ diệu của đổi thay còn nhiều hơn thế nữa...

Hình ảnh lưu niệm ngày làm việc nói lên vài chuyện.

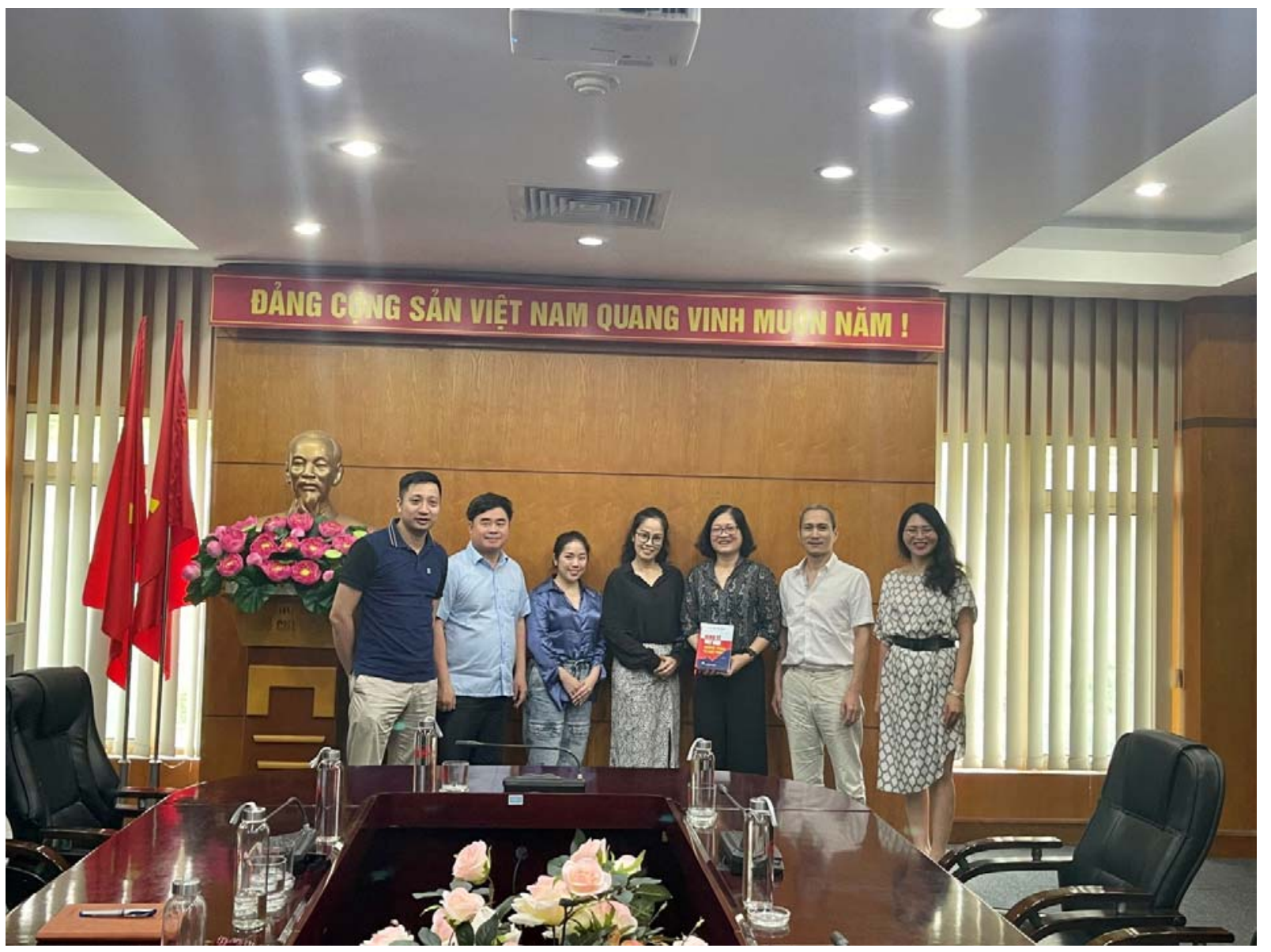

Ngày 10-7-2021 tại Nhà xuất bản Chính trị Quốc gia. 
Đầu tiên, là nói tới các bạn trẻ có liên quan trực tiếp tới các công việc chuẩn bị. Các bạn đều ở cỡ tuổi sau tôi khoảng 12-15 năm. Nghĩa là cách biệt tuổi tác tối thiểu thì cũng bằng tuổi cuốn sách. Thật là một khoảng cách dư thừa để nói rằng "mình đã có tuổi".

Thứ đến, là nói tới một trong những người biên tập/đọc sửa bản thảo thời gian đó (trong ảnh là người cầm cuốn sách trong tay). Cô ấy bây giờ cũng đã có chức vụ đâu như Vụ trưởng hay Phó Vụ trưởng. Đó là một thay đổi đáng kể về chỗ đứng của con người trong hệ thống cơ quan, sau 12 năm. Nhưng thực tế, thay đổi còn diễn ra nhiều hơn thế. Tôi nhớ tới người phụ trách của bạn biên tập này, người cũng biên tập sách giúp tôi từ tận hơn 20 năm trước [2], cũng đã hưu trí nhiều năm nay. Cũng chợt nhớ tới lãnh đạo Nxb thời kỳ đó là GS Đặng Xuân Kỳ (con trai cố Tổng bí thư Trường Chinh) cũng đã qua đời hơn chục năm trước.

Còn nữa, việc gặp ông Giám đốc - Tổng biên tập cũng thú vị, TS. Phạm Minh Tuấn (người mặc áo xanh trứng sáo trong hình). Mới trao đổi mất chưa đầy một phút, chúng tôi chợt nhận ra là đã từng quen biết nhau từ trước. Có điều, vì chủ đề và không gian công việc khác nhau, nên hầu như không có dịp gặp lại. Khoảng ngắt quãng "mới đây thôi" ấy cũng chừng 10 năm! Chúng tôi có chung một "ông anh" là TS. Nguyễn Hữu Từ. Anh Từ cũng là người viết nhận xét cho cuốn sách [1] vào khoảng tháng 4-2009. Sau khi từ Văn phòng Trung ương luân chuyển vào Bình Dương năm 2014 làm Phó bí thư, đến 2018 anh Từ không may bị bệnh nan y và qua đời, khiến mọi người rất thương tiếc. Giờ gặp lại, nói chuyện người chuyện đời, thấy bùi ngùi xúc động.

Trong một phút, cách cảm nhận kiểu người có tuổi còn kéo trôi tuột ký ức về cái thời lang thang trèo rào vặt hoa quả các nhà có vườn to đẹp quanh khu phố tôi sống thời trẻ thơ. Trèo ra trèo vào chán chê, "thu hoạch" từ ổi, táo, hồng xiêm, nho, nhãn, trứng gà... rồi mới dần được các anh em trong khu phố mách cho biết đó là các khu vườn đi kèm những tên tuổi lịch sử: Song Hào, Hoàng Văn Thái, Cù Huy Cận, Cao Văn Khánh, Văn Tiến Dũng, Tố Hữu, v.v..

(Đúng là trẻ con, điếc không sợ súng. Nhưng quả thật, nếu không có ký ức hồi bé leo trèo vào những nơi cửa quan cao rộng đó, thì bây giờ thấy cũng nhiều phần trống vắng!)

Nhưng lại có những chỗ dân nghèo thành thị như nhà bạn ở đầu phố Hàng Điếu, nơi mà các ông Trần Chung, Văn Cao và bằng hữu thi-nhạc-họa, uống rượu luận chuyện đời và thi thoảng tôi nhận chân sai vặt đi mua rượu với thằng bạn ở phố Nguyễn Văn Tố, hoặc góc Đường Thành (gần chợ Hàng Da). Chẳng có quả gì để vặt, mà vẫn thấy vui vui.

Dường như cũng chỉ “mới đây thôi”...

Tạm hình dung thế này, chỉ thêm một lần nữa nghĩ "mới đây thôi” theo cách trên-chẳng hạn khi nhắc lại về một vài cuốn sách còn mới [3] hay đang chờ phát hành ngay bây giờ [4]-thì đã thấy bản thân mình ngoài 60 tuổi, "Lục thập nhi nhĩ thuận"!

Hẳn là vào lúc đó thì cách cảm nhận lịch sử sẽ còn đậm "chất lịch sử” hơn nhiều lần nữa. 


\section{Tài liệu tham khảo:}

[1] Chính, P. M., \& Hoàng, V. Q. (2009). Kinh tế Việt Nam: Thăng trầm và đột phá. Nxb Chính trị Quốc gia, Hà Nội.

[2] Hoàng, V. Q., \& Chí, N. P. (2000). Nguyên lý tài chính-toán của thị trường chứng khoán. Nxb Chính trị Quốc gia - Sự thật, Hà Nội.

[3] Vuong, Q. H., \& Tran, T. (2019). The Vietnamese Social Sciences at a Fork in the Road. Warsaw, Poland: De Gruyter / Sciendo.

[4] Vuong, Q. H., Nguyen, M. H., \& Le, T. T. (2021). A Mindsponge-Based Investigation into the PsychoReligious Mechanism Behind Suicide Attacks. Warsaw, Poland: De Gruyter / Sciendo. 